\title{
KeSESuaian KaWaSAn Transit di Kota SuRaKarta BERdaSARKan KONSEP TRANSIT ORIENTED DEVELOPMENT
}

\author{
DWIKI KUNCARA JATI', \\ PROGRAM STUdi PERENCANAAN WILAYAH DAN KoTA \\ FAKULTAS TEKNIK \\ UNIVERSITAS SEBELAS MARET, SURAKARTA \\ email: dkuncarajati@gmail.com \\ KUSWANTO NURHADI \\ PROGRAM STUdi PERENCANAAN WILAYAH DAN KotA \\ FAKULTAS TEKNIK \\ UnIVERSITAS SEBELAS MARET, SURAKARTA \\ ERMA FITRIA RINI ${ }^{3}$ \\ PROGRAM STUDI PERENCANAAN WILAYAH DAN KOTA \\ FAKULTAS TEKNIK \\ UNIVERSITAS SEBELAS MARET, SURAKARTA
}

\begin{abstract}
T

The uncontrolled and inconsistent of urban growth triggered the growth of a new unrelated distribution center (sprawl). The problem that arises later is the emergence of congestion problems that affecting the economic, social and environmental sectors. The concept of TOD as an alternative solution to this problem by integrating transportation and spatial development in the area around the transit point. Surakarta is one of the cities that apply the concept of TOD at its transit point considering the role of Surakarta as National Activity Center (PKN) which makes itself as hinterland destination area. The purpose of this study was to assess the suitability of regional transit points with the concept of TOD. The research technique used is quantitative technique by using scoring analysis method. The result of the research mentioned that the transit area of Solopurwosari, Solobalapan and Solojebres are included in the classification which is not in accordance with TOD concept. This is because the three transit areas have not fulfilled the six principles of the TOD concept, namely density, mixed use, pedestrian, friendly cyclist, interconnection road and parking. Therefore, transitoriented planning is necessary to accommodate these six principles.
\end{abstract}

Kkeywords: Transit-Oriented Development, transit points

\section{PENDAhULUAN}

Pertumbuhan kota yang tidak terencana dan konsisten akan menimbulkan sprawl. Dampak yang ditimbulkan dengan munculnya sprawl adalah munculnya pusat-pusat distribusi yang saling terkoneksi sehingga merangsang mobilitas yang berorientasi pada pemanfaatan kendaraan pribadi (automobile). Dari hal tersebut kemudian muncul permasalahan transportasi perkotaan seperti kemacetan, penurunan kualitas udara, peningkatan angka kecelakaan, hingga pemborosan energi tak terbarukan.

Pada negara berkembang, permasalahan terkait transportasi lumrah dijumpai di kota-kota besar dan 
beberapa di antaranya bahkan sudah memasuki tahap kritis (Tamin, 2000). Di Indonesia, hal tersebut dapat dibuktikan dengan hasil kajian SITRAMP (Study on Integrated Transportation Master Plan) tahun 2004 yang menunjukkan bahwa kecepatan rata-rata lalu lintas di DKI Jakarta hanya mencapai $20,21 \mathrm{~km} / \mathrm{jam}$ tiap harinya (Srihadi, 2010). Rendahnya kecepatan rata-rata lalu lintas di DKI Jakarta disebabkan oleh berbagai faktor, diantaranya adalah peningkatan jumlah kendaraan pribadi serta belum berkembangnya pemanfaatan moda transportasi publik. Guna mengatasi permasalahan tersebut, diperlukan suatu konsep pengembangan kawasan berorientasi pada transportasi berkelanjutan, efektif, dan efisien.

Transit Oriented Development (TOD) merupakan salah satu konsep pengembangan kawasan perkotaan yang mengutamakan pemanfaatan transportasi publik daripada kendaraan pribadi. Curtis (dalam Bishop 2015) mengemukakan tujuan pengembangan kawasan dengan konsep TOD yaitu guna mengurangi ketergantungan penggunaan kendaraan pribadi dengan meningkatkan penggunaan transportasi umum massal dan mempromosikan pembangunan tanpa menciptakan sprawl. Penerapan konsep TOD pada kawasan perkotaan sejatinya merupakan ciri dari penerapan smart growth. Sesuai dengan penerapan smart growth, pengembangan lahan pada kawasan transit TOD harus mempromosikan efisiensi pengembangan lahan. Fungsi komersial, permukiman, perkantoran, perparkiran, dan fasilitas umum yang dikembangkan dalam jangkauan pejalan kaki dimaksudkan untuk membentuk jarak tempuh yang minimal (Dittmar et al, 2003). Fungsi-fungsi strategis tersebut kemudian diakomodir oleh transportasi publik yang dihubungkan dengan titik transit. Perencanaan kota yang matang dan menyeluruh mutlak diperhitungkan mengingat konsep TOD tidak dapat terwujud tanpa mengaitkan pengembangan transportasi dengan pengembangan tata ruang titik transit.

Kota Surakarta merupakan salah satu kota di Jawa Tengah yang berfungsi sebagai Pusat Kegiatan Nasional (PKN). Peran tersebut menjadikan Surakarta sebagai daerah tujuan kawasankawasan hinterland di sekitarnya, yang berdampak terhadap peningkatan intensitas pergerakan internal maupun pergerakan regional Kota Surakarta. Kondisi ini terlihat dari tingginya tingkat kejenuhan ruas jalan di Kota Surakarta, terutama ruas jalan yang melewati kawasan pusat kota (Dishubkominfo Kota Surakarta, 2009). Guna mengatasi permasalahan tersebut, Pemerintah Kota Surakarta dalam Rencana Tata Ruang Wilayah (RTRW) Kota Surakarta Tahun 2011 - 2031 menggunakan pendekatan perencanaan konsep TOD untuk mengembangkan titik-titik transit yang tersebar di wilayah Kota Surakarta. Titik transit tersebut berupa terminal/stasiun antarmoda pada pusatpusat kegiatan, stasiun angkutan jalan rel, shelter angkutan massal jalan raya (halte) dan terminal angkutan umum. Selain itu untuk mendukung konsep TOD, Kota Surakarta mengembangkan transportasi masal berupa BRT (Bus Rapid Transit) dengan nama BST yang telah memiliki rute tiga koridor.

Namun dalam pelaksanaannya, perencanaan konsep TOD tidak dapat dicapai hanya dengan melihat peran titik transit sebagai tempat naik dan turun penumpang atau dengan menyediakan transportasi umum massal yang cepat dan menarik bagi masyarakat saja. Pengembangan kawasan berkonsep TOD memerlukan kajian yang mendalam mengenai titik transit beserta kawasan sekitar titik transit yang menunjang aktivitas transit. Hal tersebut sejalan dengan pemikiran Oregom Reviser Statues (dalam TCRP 2002) yang mengatakan bahwa salah satu kunci dalam menerapkan konsep TOD adalah pemanfaatan guna lahan campuran (mixed-use) pada kawasan 
transit. Selanjutnya, penelitian ini akan fokus mengkaji titik-titik transit skala regional yang dilalui oleh rute BST yang berperan sebagai transportasi umum masal untuk membatasi jumlah obyek penelitian yang dikaji.

\section{TINJAUAN PUSTAKA}

\subsection{Struktur Kawasan TOD}

Dalam proses perencanaan kawasan transit pada konsep TOD, perlu dilakukan identifikasi terkait batas antara kawasan TOD dan kawasan nonTOD untuk mencegah sprawl.

TCRPC (2012) mengklasifikasikan kawasan TOD menjadi empat area:

A. Premium transit station, yaitu titik transit yang melayani moda transportasi massal premium (kereta api komuter, light rail, bus rapid transit).

B. Transit core, adalah area transit yang berada dalam radius seperempat mil (400 meter) dari titik transit utama dengan luas area mencapai 125 acre (50 ha).

C. Transit neighbourhood, merupakan area setelah pusat transit yang berjarak setengah mil (500 meter) dari titik transit utama dengan luas mencapai 375 acre (151 ha).

D. Transit supportive area adalah area pendukung transit dengan jarak $1 \mathrm{mil}$ (1600 meter) dari titik transit utama.

TCPC kemudian mengklasifikiasikan kawasan TOD (TOD Station Area) adalah kawasan yang mencakup transit core dan transit neighborhood. Berikut merupakan ilustrasi pembagian area pada kawasan dengan konsep TOD.

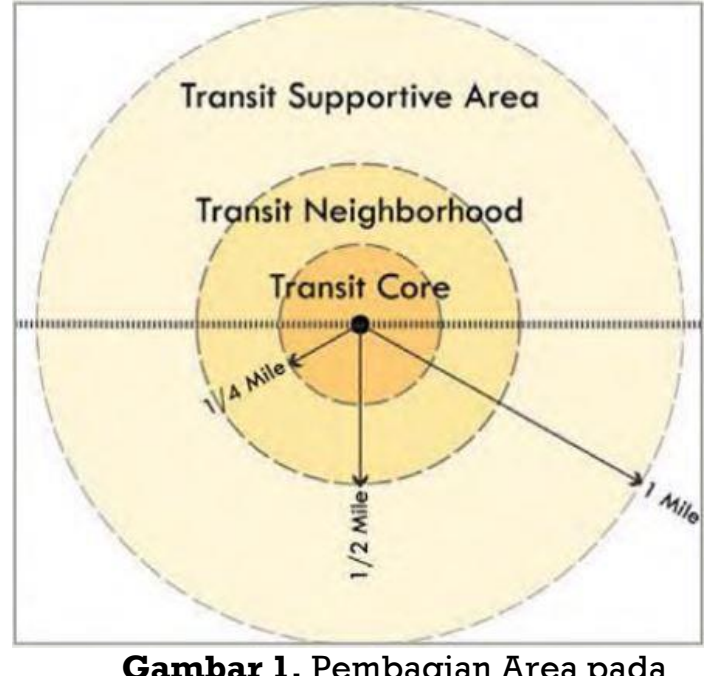

Gambar 1. Pembagian Area pada Kawasan TOD

Sumber: TCRPC, 2012

Calthorpe (dalam Griffin 2004) membagi lima segmen area pada kawasan TOD berdasarkan karakteristik guna lahan yang ada.

A. Fasilitas publik, merupakan area dengan karakteristik fungsi guna lahan sebagai pendukung aktivitas masyarakat, memiliki tingkat visibilitas yang tinggi dengan ciri fisik umumnya dilengkapi dengan ruang publik berupa taman atau plaza. Jenis pemanfaatan ruang lainya yang dapat dikembangkan di dalam area ini adalah kantor pemerintahan, perpustakaan, kantor polisi, kantor pemadam kebakaran, serta jenis pemanfaatan ruang lainnya yang berorientasi pada pemenuhan kepentingan publik.

B. Pusat komersial adalah area yang dimanfaatkan untuk kepentingan komersial berupa retail, perkantoran, rumah makan, pusat hiburan (bioskop/mall), industri ringan, serta fungsi komersial lainnya. Area pusat komersial berada di pusat kawasan TOD dan berada dekat dengan lokasi titik transit sehingga dapat diakses dengan berjalan kaki, serta dilengkapi dengan keberadaan ruang hijau.

C. Permukiman merupakan area yang berada di sekitar area pusat (titik 
transit, fasilitas publik, dan pusat komersial) dengan dominasi guna lahan permukiman dengan tipe, kepadatan, dan harga yang bervariasi.

D. Secondary area merupakan area yang berada di luar kawasan transit dengan dominasi pergerakan menggunakan kendaraan pribadi serta kepadatan bangunan yang relatif rendah. Jenis pemanfaatan ruang yang ada pada area ini adalah hunian tipe rumah tunggal, sekolah umum, kawasan industri besar, serta permukiman perdesaan.

E. Fungsi-fungsi lain merupakan segmen area yang memiliki karakteristik guna lahan di luar fungsi fasilitas umum, permukiman, pusat komersial, maupun secondary area. Segmen ini dapat berada di dalam maupun di luar kawasan transit, dengan jenis pemanfaatan ruang berupa zona riparian dan sempadan jalur kereta api.

\subsection{Prinsip dan Indikator Konsep TOD}

Dalam proses pengembangan kawasan berbasis TOD, perlu diketahui karakteristik utama yang mencirikan penerapan konsep TOD. Karakteristik tersebut dijabarkan secara lebih rinci ke dalam prinsip dan indikator konsep TOD. Prinsip dan indikator tersebut disarikan dari beberapa literatur yang dirumuskan oleh institusi pegiat pembangunan kota dan transportasi seperti Florida Department of Transportation (TCRPC), Institute for Transportation and Development Policy (ITDP) dan Calthorpe Associates. Berikut adalah prinsip dan indikator konsep TOD:

A. Kepadatan atau densify adalah pembentukan pola dan tata ruang yang rapat serta padat, dengan menekankan pertumbuhan kota secara vertikal (densifikasi) daripada pertumbuhan kota secara horizontal (sprawl). Menurut TCRP (2002) dan
TCRPC (2012) tingkat kepadatan hunian atau properti menjadi indikator yang dapat menjelaskan prinsip kepadatan. Sementara ITDP (2015) cenderung memperhatikan tingkat kepadatan penggunaan lahan, dengan berpedoman pada nilai koefisien dasar bangunan (KDB) dan koefisien lantai bangunan (KLB). Kepadatan penggunaan lahan akan mendekatkan berbagai aktivitas hingga pemanfaatan moda transportasi umum dapat dimaksimalkan.

B. Land-Use Mixes bertujuan untuk mendukung efisiensi mobilitas dan meningkatkan livability kawasan dengan mengintegrasikan hunian dengan tempat bekerja, tempat berbelanja, dan sekolah. Prinsip mix bertujuan untuk mendekatkan antar guna lahan yang berkaitan sehingga akan mendorong aktivitas berjalan dan bersepeda masyarakat sekitar (ITDP, 2015). TCRP (2002) membagi indikator mixed-uses ke dalam dua hal yaitu jumlah guna lahan mixeduses dan keberadaan retail dengan skala pelayanan yang beragam.

C. Jalur Pedestrian dibutuhkan untuk mendukung pergerakan yang berorientasi pada penggunaan transportasi umum massal, dengan menyediakan infrastruktur yang mampu memberikan kenyamanan dan keamanan bagi pejalan kaki juga termasuk pesepeda.

D. Interkoneksi jaringan jalan dan blok dibutuhkan guna membentuk lingkungan yang walkable. Jaringan jalan yang padat dengan komposisi jalan-jalan kecil dan jumlah persimpangan yang tinggi akan memperlambat laju kendaraan sehingga dapat memberikan keuntungan bagi para pejalan kaki. Untuk mengetahui tingkat interkoneksi jaringan jalan dan blok, indikator yang dapat digunakan yaitu dengan menghitung jumlah persimpangan yang ada di suatu kawasan. Semakin banyak 
persimpangan yang ditemui maka semakin tinggi tingkat interkoneksi jaringan jalan dan blok.

E. Parkir dalam konsep TOD diarahkan pada sistem pembatasan parkir dengan penyediaan ruang parkir yang lebih sedikit pada pusat kawasan transit dibandingkan pada area pinggiran kota/secondary area (TCRPC, 2012). Salah satu metode pembatasan lahan parkir menurut TCRPC adalah metode parkir disrictwide dengan menyediakan parkir kolektif. Metode ini mampu mengakomodasi kebutuhan parkir di titik transit dan atau kawasan transit dengan meningkatkan efisiensi lahan dan membatasi lahan parkir individu. Parkir dengan metode ini biasanya berupa gedung parkir, kantong parkir, atau fasilitas parkir titik transit itu sendiri.

F. Ruang terbuka berperan sebagai wadah interaksi sosial sekaligus menciptakan keserasian lansekap di tengah tingginya intensitas pemanfaatan lahan. Lokasi ruang terbuka pada kawasan berkonsep TOD bisa berada di dekat titik transit, sempadan jalan, area permukiman, atau di area sekitar peruntukkan retail.

\section{METODE PENELITIAN}

Metode penelitian ini berisi ruang lingkup penelitian dan metode analisis yang digunakan, yaitu sebagai berikut:

\subsection{Ruang Lingkup}

Ruang lingkup wilayah dalam penelitian ini mencakup seluruh kawasan transit untuk titik transit skala pelayanan regional di Kota Surakarta. Titik-titik transit tersebut adalah Stasiun Purwosari, Stasiun Solo Balapan, dan Stasiun Solo Jebres. Batasan area didasarkan pada jangkauan titik transit di kawasan TOD yang disesuaikan dengan jarak maksimal pejalan kaki yaitu sejauh 800 meter dari lokasi titik transit (TCRP, 2002).

Ruang lingkup wilayah penelitian tersebut dapat dilihat pada Gambar 2. 



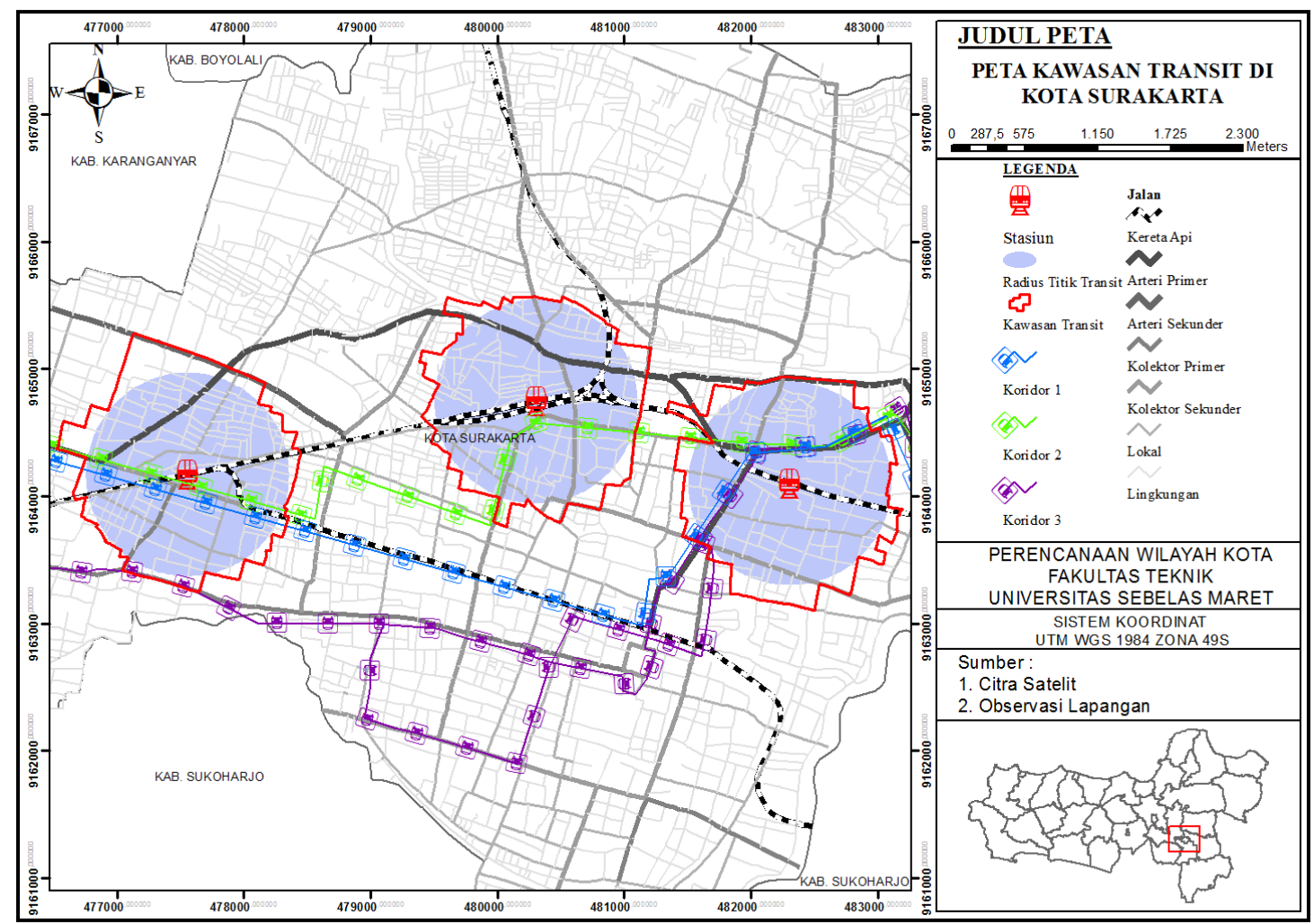

Gambar 2. Peta Wilayah Penelitian

Sumber: Analisis Penulis, 2017

\subsection{Pendekatan Penelitian}

Pendekatan yang digunakan dalam penelitian ini adalah pendekatan deduktif. Pendekatan deduktif adalah model pendekatan yang memiliki karakteristik berupa peneliti mengkaji pertanyaan penelitian dengan teori yang kemudian diturunkan dalam bentuk variabel-variabel. Sesuai dengan karakteristik alur pendekatan deduktif, penelitian ini dimulai dengan menguji teori prinsip-prinsip kawasan TOD beserta indikatornya. Sintesis teori tersebut kemudian menghasilkan beberapa variabel yang kemudian dioperasionalkan guna merumuskan kebutuhan data. Data yang diperoleh kemudian diolah untuk menjawab kesesuaian kawasan transit di Kota Surakarta berdasarkan konsep TOD.

\subsection{Variabel Penelitian dan Teknik Pengumpulan Data}

Pada penelitian ini terdapat enam variabel penelitian yang akan dijabarkan lebih rinci melalui sub variabel dan sub-sub variabel. Berikut definisi operasional masing-masing variabel yang disajikan pada Tabel 1 . Pengumpulan data dilakukan secara primer dan sekunder. Data primer diperoleh dari hasil observasi lapangan dan wawancara. Sementara data sekunder didapatkan dari proses studi dokumen dan interpretasi peta.

Tabel 1. Operasional Variabel

\begin{tabular}{|c|c|c|c|c|c|c|c|}
\hline \multirow[b]{2}{*}{ No } & \multirow[b]{2}{*}{ Variabel } & \multirow[b]{2}{*}{$\begin{array}{c}\text { Sub } \\
\text { Variabel }\end{array}$} & \multirow[b]{2}{*}{ Indikator } & \multirow[b]{2}{*}{ Skor } & \multicolumn{2}{|c|}{ Klasifikasi } & \multirow[b]{2}{*}{ Dasar } \\
\hline & & & & & Sesuai & $\begin{array}{l}\text { Tidak } \\
\text { Sesuai }\end{array}$ & \\
\hline \multirow[t]{2}{*}{1} & \multirow[t]{2}{*}{ Kepadatan } & \multirow{2}{*}{$\begin{array}{l}\text { Guna } \\
\text { Lahan } \\
\text { Padat }\end{array}$} & $\begin{array}{l}\text { Tingkat rata-rata koefisien dasar } \\
\text { bangunan tinggi }\end{array}$ & 0,5 & \multirow[t]{2}{*}{$2-1,1$} & \multirow[t]{2}{*}{$0-1$} & TCRP (2002) \\
\hline & & & Tingkat rata-rata koefisien lantai & 0,5 & & & TCRP (2002) \\
\hline
\end{tabular}




\begin{tabular}{|c|c|c|c|c|c|c|c|}
\hline \multirow{4}{*}{ No } & \multirow{4}{*}{ Variabel } & \multirow{2}{*}{$\begin{array}{l}\text { Sub } \\
\text { Variabel }\end{array}$} & \multirow[b]{2}{*}{ Indikator } & \multirow[b]{2}{*}{ Skor } & \multicolumn{2}{|c|}{ Klasifikasi } & \multirow[b]{2}{*}{ Dasar } \\
\hline & & & & & Sesuai & $\begin{array}{l}\text { Tidalk } \\
\text { Sesuai }\end{array}$ & \\
\hline & & & bangunan tinggi & & & & \\
\hline & & $\begin{array}{l}\text { Kepadatan } \\
\text { Hunian }\end{array}$ & Tingkat kepadatan hunian tinggi & 1 & & & TCRP (2002) \\
\hline \multirow{4}{*}{2} & \multirow{4}{*}{$\begin{array}{l}\text { Guna } \\
\text { Lahan } \\
\text { Campuran }\end{array}$} & Guna & Persentase area pusat seimbang & 0,33 & \multirow{4}{*}{$2-1,1$} & \multirow{4}{*}{$0-1$} & TCRP (2002) \\
\hline & & Lahan & Persentase area hunian seimbang & 0,33 & & & TCRP (2002) \\
\hline & & Seimbang & Persentase area publik seimbang & 0,33 & & & TCRP (2002) \\
\hline & & $\begin{array}{l}\text { Retail } \\
\text { Bervariasi }\end{array}$ & $\begin{array}{l}\text { Ketersediaan retail dengan skala } \\
\text { pelayanan yang lengkap }\end{array}$ & 1 & & & $\begin{array}{l}\text { TCRP (2002), } \\
\text { ITDP (2015) }\end{array}$ \\
\hline \multirow{2}{*}{3} & \multirow{2}{*}{$\begin{array}{l}\text { Ramah } \\
\text { Pejalan } \\
\text { Kaki dan } \\
\text { Pesepeda }\end{array}$} & $\begin{array}{l}\text { Ramah } \\
\text { Pejalan } \\
\text { Kaki }\end{array}$ & $\begin{array}{l}\text { Ketersediaan infrastruktur } \\
\text { pedestrian yang aman dan nyaman } \\
\text { bagi pejalan kaki }\end{array}$ & 1 & \multirow{2}{*}{$2-1,1$} & \multirow{2}{*}{$0-1$} & ITDP (2015) \\
\hline & & $\begin{array}{l}\text { Ramah } \\
\text { Pesepeda }\end{array}$ & $\begin{array}{l}\text { Ketersediaan sarana prasarana } \\
\text { untuk pesepeda yang aman dan } \\
\text { lengkap }\end{array}$ & 1 & & & ITDP (2015) \\
\hline 4 & $\begin{array}{l}\text { Interkonek } \\
\text { si Jalan }\end{array}$ & - & $\begin{array}{l}\text { Jumlah rata-rata persimpangan } \\
\text { tinggi }\end{array}$ & 1 & 1 & 0 & TCRPC (2012) \\
\hline 5 & Parkir & - & $\begin{array}{l}\text { Ketersediaan parkir kolektif } \\
\text { dengan daya tampung memadai }\end{array}$ & 1 & 1 & 0 & TCRPC (2012) \\
\hline 6 & $\begin{array}{l}\text { Ruang } \\
\text { Terbuka }\end{array}$ & - & $\begin{array}{l}\text { Ketersediaan ruang terbuka } \\
\text { sebagai community hub }\end{array}$ & 1 & 1 & 0 & TCRPC (2012) \\
\hline \multicolumn{4}{|c|}{ Total Skor } & 9 & & & \\
\hline
\end{tabular}

Sumber: Analisis Peneliti dari Berbagai Sumber, 2017

\subsection{Teknik Analisis}

Penelitian ini menggunakan metode kuantitatif, dengan menggunakan beberapa teknik analisis yaitu sebagai berikut:

A. Teknik Analisis Skoring Kesesuaian Tiap Variabel. Analisis ini bertujuan untuk melihat kesesuaian kawasan transit berdasarkan variabelvariabel penelitian. Pemberian bobot angka tiap variabel didasarkan pada masing-masing variabel. Sementara, tiap indikator mendapatkan skor 1 (satu) apabila termasuk dalam kategori "sesuai" dan 0 (nol) apabila termasuk dalam kategori "tidak sesuai". Penilaian ini menggunakan standar Guttman sebagai dasar untuk mendapatkan jawaban berupa pilhan ganda atau bernilai "ya atau tidak" (Sugiyono, 1999). Hasil perhitungan skoring dari masing-masing variabel kawasan transit kemudian digunakan sebagai masukan untuk analisis kesesuaian kawasan transit terhadap konsep TOD.

B. Teknik Analisis Kesesuaian Kawasan Transit sebagai Kawasan TOD. Analisis ini dilakukan untuk mengetahui kondisi kesesuaian kawasan transit sebagai kawasan yang berorientasi transit. Analisis ini diawali dengan menjumlahkan skor pada tiap kawasan dan mengkonversikannya ke dalam bentuk persentase dengan rumus berikut:

Persentase skor $=\frac{\text { Jumlah } \text { skor kawasan }}{\text { Jumlah skor maksimal }} \times 100 \%$

Hasil persentase skor kawasan tersebut kemudian diklasifikan kedalam rentang skala Guttman (Sugiyono, 1999) sebagai berikut:

- Apabila skor suatu kawasan transit berada dalam rentang skala 0-49\%, maka kawasan transit tersebut dinyatakan dengan "mendekati tidak sesuai" berdasarkan konsep TOD,

- Apabila skor suatu kawasan transit bernilai $50 \%$ maka kawasan transit tersebut dinyatakan "mendekati tidak sesuai dan sesuai" berdasarkan konsep TOD,

- Apabila skor suatu kawasan transit berada dalam rentang skor 51-100\%, maka kawasan transit 
tersebut dinyatakan "mendekati sesuai" berdasarkan konsep TOD.

\section{HASIL DAN PEIMBAHASAN}

Pada bagian ini akan terlebih dahulu diberikan gambaran umum terkait ketiga kawasan transit yang ada di Kota Surakarta. Diawali dengan kawasan transit Solopurwosari yang mencakup kawasan sekitar Stasiun Solopurwosari dengan capaian luas 231,55 ha. Stasiun Purwosari melayani pemberangkatan kereta api jarak jauh, lokal, dan kereta wisata. Kawasan transit Solopurwosari meliputi kelurahan Sondakan, Kerten, Purwosari, Pajang, dan Manahan. Kawasan transit Solopurwosari dilalui dua jalan arteri primer yaitu Jl. Jend. Ahmad Yani dan Jl Brigjen Slamet
Riyadi dan dua jalan arteri sekunder yaitu Jl. LU Adi Sucipto dan Jl. Brigjen Slamet Riyadi (Dishubkominfo Kota Surakarta, 2009). Jalan tersebut berfungsi menghubungkan pusat kegiatan nasional Jawa Tengah-DIY dengan pusat kegiatan nasional Jawa Timur. Kawasan transit Solopurwosari juga dilengkapi dengan jalur citywalk di sepanjang Jalan Brigjen Slamet Riyadi yang membentang dari Stasiun Purwosari hingga Perempatan Gladhak, Kampung Baru. Dari segi penggunaan lahan, kawasan ini didominasi oleh guna lahan permukiman dan guna lahan perdagangan serta jasa yang mengelompok di sepanjang Jalan Brigjen Slamet Riyadi. Berikut ini adalah peta kawasan transit Solopurwosari.

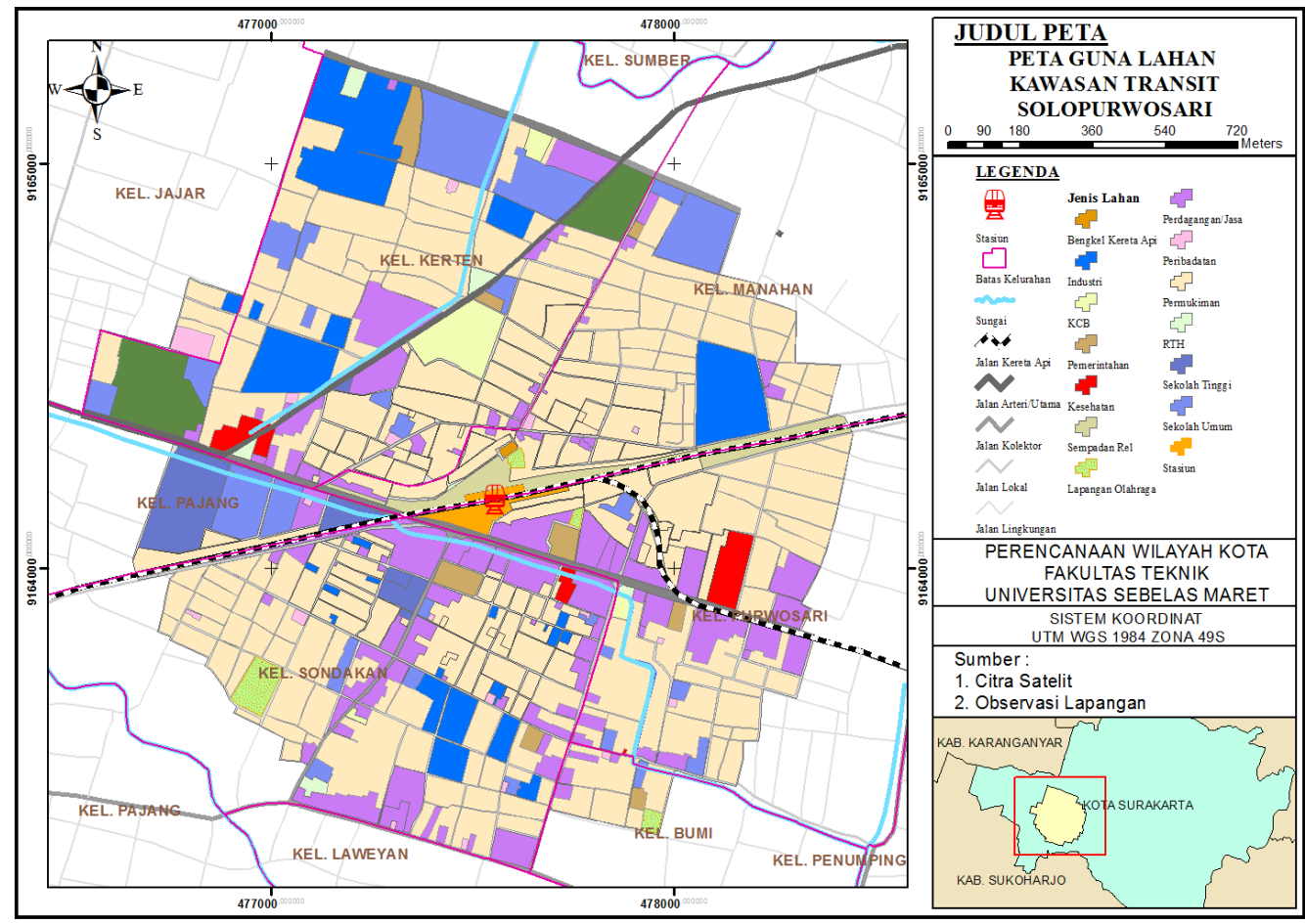

Gambar 3. Peta Kawasan Transit Solopurwosari Sumber: Analisis Penulis, 2017

Kawasan Transit Solobalapan adalah kawasan sekitar Stasiun Solobalapan dengan luas mencapai 200 ha yang mencakup tujuh kelurahan antara lain kelurahan Nusukan,
Manahan, Gilingan, Kestalan, Setabelan, Ketelan dan Punggawan. Stasiun Solobalapan sendiri adalah yang juga melayani kereta api pemberangakatan jarak jauh dan 
kereta pemberangkatan lokal seperti Stasiun Solopurwosari. Berdasarkan informasi laman resmi Dishubkominfo Surakarta, pengembangan Stasiun Solobalapan direncakan akan saling terintegrasi antara Stasiun Solobalapan, Terminal Tirtonadi dan Bandara Adi Sumarmo, Boyolali. Dalam aspek guna lahan, Kawasan Transit Solobalapan didominasi guna lahan permukiman di sebelah utara dan barat kawasan tepatnya di Kelurahan Nusukan dan
Mangkubumen serta guna lahan perdagangan jasa yang tersebar di Kelurahan Setabelan, Kestalan dan Gilingan. Sementara dalam aspek transportasi kawasan ini dilalui jalan arteri primer (Jl. Jend. Ahmad Yani), jalan kolektor primer (Jl Kapten Piere Tendean) dan jalan kolektor sekunder (Jl. Sutan Syahrir, Jl. Letjen. S. Parman, Jl. Monginsidi, Jl. Gajah Mada). Berikut adalah peta kawasan transit Solobalapan.

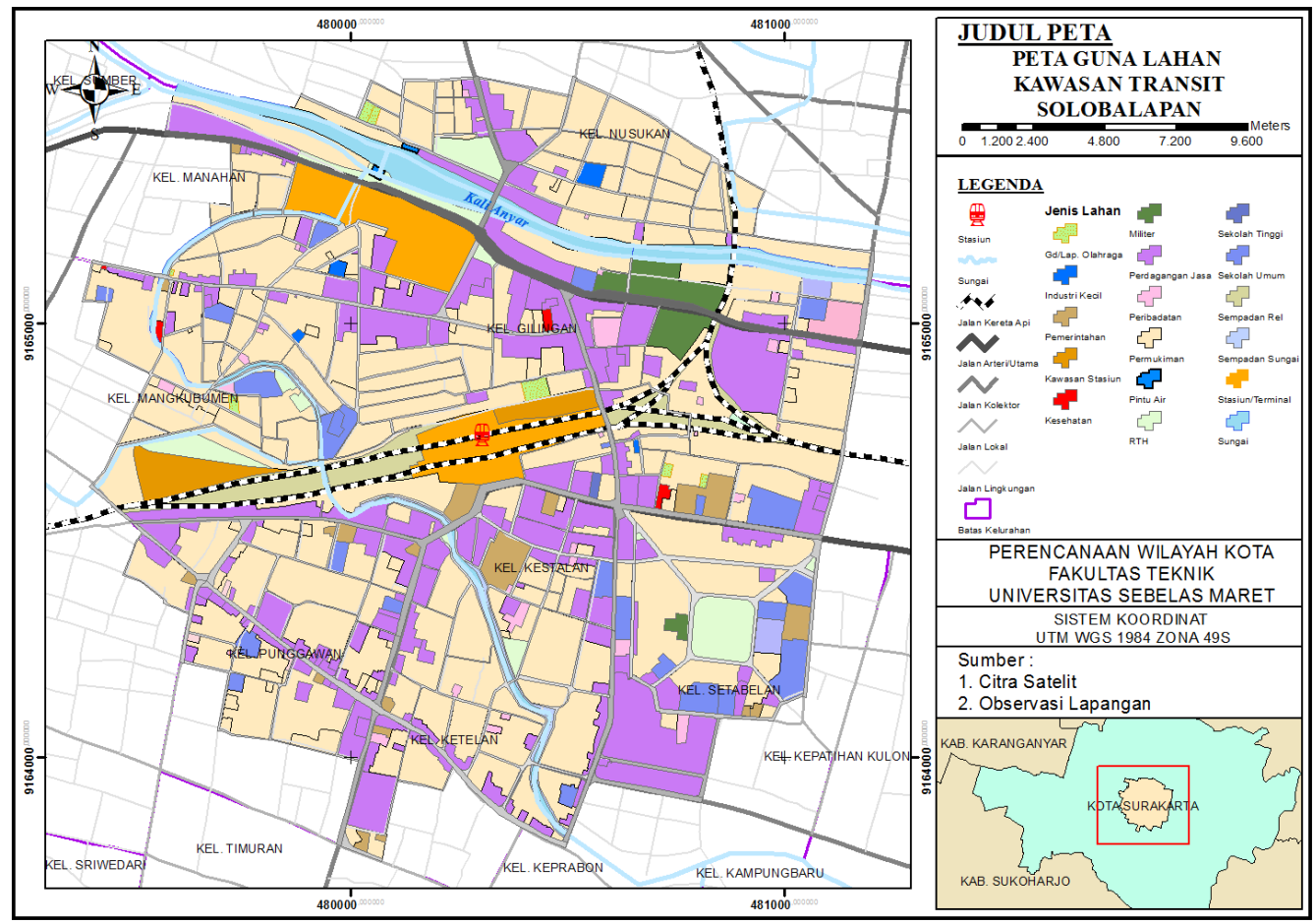

Gambar 4. Peta Kawasan Transit Solobalapan Sumber: Analisis Penulis, 2017

Kawasan Transit Solojebres merupakan kawasan transit yang berpusat di Stasiun Solojebres dengan cakupan luas mencapai 217 ha. Kawasan ini tersusun dari sembilan kelurahan, yaitu: kelurahan Tegalharjo, Gilingan, Jebres, Kepatihan Wetan, Kepatihan Kulon, Purwodiningratan, Jagalan, Gadegan dan Sudiroprajan. Stasiun Solojebres sendiri adalah stasiun yang hanya melayani penumpang kereta api jarak jauh kelas ekonomi. Dalam aspek transportasi, kawasan ini dilalui fungsi jalan arteri primer yaitu, Jl. Jend. Ahmad Yani dan Jl. Kolonel Sutarto serta jalan arteri sekunder yaitu: Jl. Urip Sumoharjo dan Jl. Tentara Pelajar. Dalam aspek guna lahan, kawasan transit Solojebres sebelah utara didominasi dengan guna lahan permukiman dan fasilitas umum. Fasilitas umum tersebut merupakan fasilitas kesehatan dengan skala pelayanan nasional antara lain: RS. Dr. Moewardi, RS. dr. Oen dan Balai Besar Rehabilitasi Sosial Bina Daksa Prof.Dr.Soeharso dan fasilitas kesehatan skala regional yaitu RS Hermina. Sementara penggunaan lahan perdagangan dan jasa mendominasi penggunaan lahan di sepanjang Jalan Urip Sumoharjo dan Jalan Kolonel 
Sutarto. Dalam hal penyediaan hunian, di kawasan transit Solojebres terdapat rumah susun sewa yang mampu menyediakan hunian sebanyak 98 unit. Berikut ini adalah peta kawasan transit Solojebres.

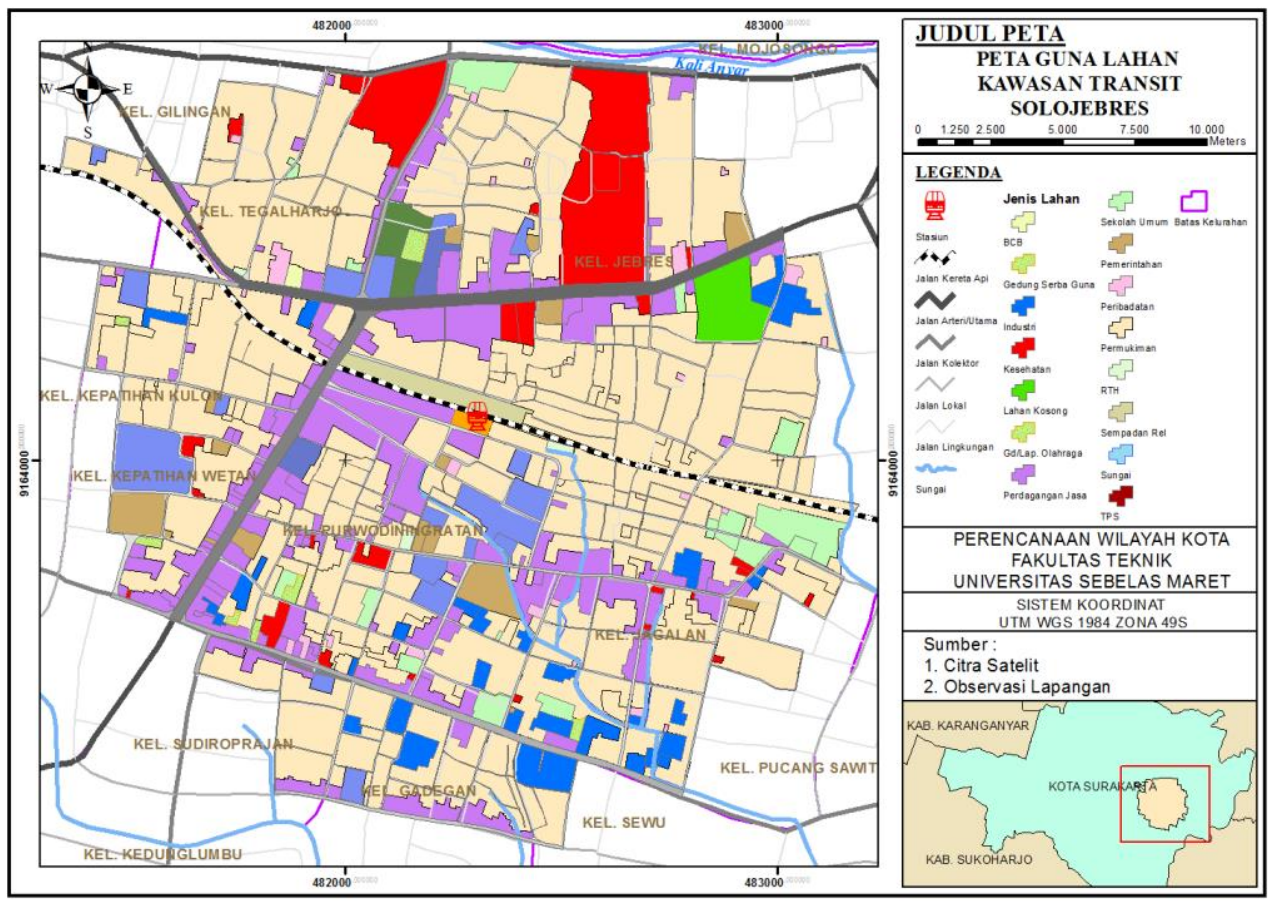

Gambar 5. Peta Kawasan Transit Solojebres Sumber: Analisis Penulis, 2017

\subsection{Analisis Skoring Kesesuaian Tiap Variabel}

\section{Analisis skoring kesesuaian variabel dilakukan dengan} membandingkan kondisi eksisting tiap variabel pada masing-masing kawasan transit dengan tolok ukur variabel kawasan transit berdasarkan konsep
TOD. Skala penilaian yang digunakan dalam analisis ini adalah model skala Guttman, yaitu variabel mendapatkan nilai 1 (satu) apabila diperoleh hasil analisis yang tidak sesuai dan mendapatkan nilai 0 (nol) apabila diperoleh hasil analisis yang tidak sesuai.

Tabel 2. Hasil Analisis Skoring Kesesuaian Tiap Variabel pada Kawasan Transit dengan Konsep TOD

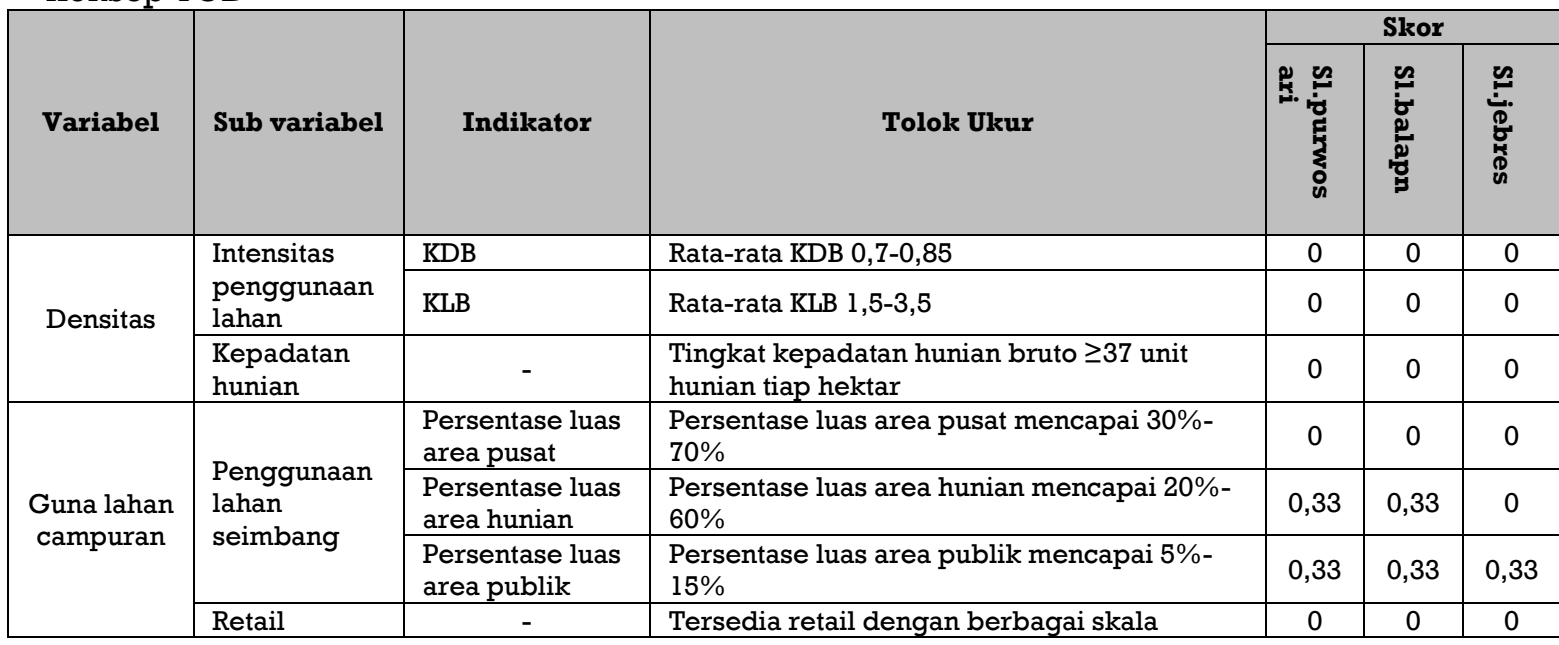




\begin{tabular}{|c|c|c|c|c|c|c|}
\hline \multirow[b]{2}{*}{ Variabel } & \multirow[b]{2}{*}{ Sub variabel } & \multirow[b]{2}{*}{ Indikator } & \multirow[b]{2}{*}{ Tololk Ukur } & \multicolumn{3}{|c|}{ Skor } \\
\hline & & & & ֻ. & 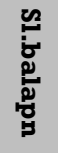 & 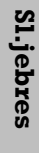 \\
\hline & bervariasi & & pelayanan & & & \\
\hline \multirow{2}{*}{$\begin{array}{l}\text { Ramah } \\
\text { pejalan } \\
\text { kaki dan } \\
\text { pesepeda }\end{array}$} & $\begin{array}{l}\text { Pedetrian } \\
\text { aman dan } \\
\text { nyaman }\end{array}$ & - & $\begin{array}{l}\text { Tersedia jalur pedestrian dengan lebar } \\
\text { minimal 1,5 m untuk jalan dengan intensitas } \\
\text { tinggi }\end{array}$ & 0 & 0 & 0 \\
\hline & $\begin{array}{l}\text { Sarana } \\
\text { prasarana } \\
\text { pespeda } \\
\text { aman dan } \\
\text { lengkap } \\
\end{array}$ & - & $\begin{array}{l}\text { Tersedia jalur khusus pesepda untuk jalan } \\
\text { dengan kecepatan diatas } 30 \mathrm{~km} / \mathrm{jam} \text { dan } \\
\text { fasilitas parkir sepeda di sekitar titik transit } \\
\text { dan sekitar bangunan dengan luas lantai } 500 \\
\mathrm{~m}^{2}\end{array}$ & 0 & 0 & 0 \\
\hline $\begin{array}{l}\text { Interkonek } \\
\text { si jalan }\end{array}$ & - & - & $\begin{array}{l}\text { Rata-rata persimpangan di kawasan transit } \geq \\
0,4 / \text { ha }\end{array}$ & 1 & 1 & 1 \\
\hline Parkir & - & - & $\begin{array}{l}\text { Ketersediaan parkir kolektif dengan daya } \\
\text { tampung yang memadai }\end{array}$ & 0 & 0 & 0 \\
\hline $\begin{array}{l}\text { Ruang } \\
\text { terbuka }\end{array}$ & - & - & $\begin{array}{l}\text { Ketersediaan ruang terbuka yang dapat } \\
\text { berperan sebagai community hubs }\end{array}$ & 1 & 1 & 0 \\
\hline
\end{tabular}

Sumber: Analisis Peneliti, 2017

Tabel 3. Kesesuaian Masing-Masing Variabel Konsep TOD Tiap Kawasan Transit

\begin{tabular}{|c|l|c|c|c|}
\hline $\begin{array}{c}\text { Kawasan } \\
\text { transit }\end{array}$ & \multicolumn{1}{|c|}{ Variabel } & Skor & Klasifikasi & $\begin{array}{c}\text { Total } \\
\text { Skor }\end{array}$ \\
\hline \multirow{5}{*}{ Solopurwosari } & Densitas & 0,0 & Tidak sesuai & Tidak sesuai \\
\cline { 2 - 4 } & Guna lahan campuran & 0,67 & Tidak sesuai \\
\cline { 2 - 4 } & Ramah pejalan kaki \& pesepeda & 0,0 & Sesuai \\
\cline { 2 - 4 } & Interkoneksi jalan & 1,0 & Tidak sesuai \\
\cline { 2 - 4 } & Parkir & 0,0 & Sesuai \\
\cline { 2 - 4 } & Ruang terbuka & 1,0 & Tidak sesuai \\
\hline \multirow{5}{*}{ Solobalapan } & Densitas & 0,0 & Tidak sesuai \\
\cline { 2 - 4 } & Guna lahan campuran & 0,67 & Tidak sesuai \\
\cline { 2 - 4 } & Ramah pejalan kaki \& pesepeda & 0,0 & Sesuai \\
\cline { 2 - 4 } & Interkoneksi jalan & 1,0 & Tidak sesuai \\
\cline { 2 - 4 } & Parkir & $1,0,0$ & Sesuai \\
\cline { 2 - 4 } & Ruang terbuka & 0,0 & Tidak sesuai \\
\hline \multirow{5}{*}{ Solojebres } & Densitas & 0,33 & Tidak sesuai \\
\cline { 2 - 4 } & Guna lahan campuran & 0,0 & Tidak sesuai \\
\cline { 2 - 4 } & Ramah pejalan kaki \& pesepeda & 1,0 & Sesuai \\
\cline { 2 - 4 } & Interkoneksi jalan & 0,0 & Tidak sesuai \\
\cline { 2 - 4 } & Parkir & 0,0 & Tidak sesuai \\
\cline { 2 - 4 } & Ruang terbuka & & \\
\hline
\end{tabular}

Sumber: Analisis Peneliti, 2017

Berdasarkan kedua tabel di atas, kondisi eksisting variabel densitas, variabel guna lahan campuran, variabel ramah pejalan kaki \& pesepeda serta variabel parkir di setiap kawasan transit termasuk dalam klasifikasi tidak sesuai dengan kondisi ideal kawasan transit berdasarkan konsep TOD. Sementara variabel yang termasuk dalam klasifikasi sesuai untuk setiap kawasan transit adalah kondisi eksisting interkoneksi jalan. Ketiga kawasan transit memiliki rata-rata persimpangan $\geq 0,4 /$ ha sehingga dapat dikatakan memenuhi variabel interkoneksi jalan dan blok pada kawasan TOD. Sementara berdasarkan kondisi eksisting variabel ruang terbuka, kawasan transit Solopurwosari dan Solobalapan termasuk dalam klasifikasi sesuai karena dilengkapi dengan ruang terbuka yang dapat berperan sebagai community hub.

\subsection{Analisis Kesesuaian Kawasan Transit terhadap Konsep TOD}

Dari hasil analisis skoring kesesuaian pada tiap variabel, maka diperoleh hasil persentase skor 
Dwiki Kuncara Jati dkk, Kesesuaian Kawasan Transit ...

kawasan beserta klasifikasi

kesesuaiannya sebagai berikut:

Tabel 3. Hasil Skor Kawasan Transit Kota Surakarta

\begin{tabular}{|l|l|l|l|}
\hline $\begin{array}{c}\text { Kawasan } \\
\text { Transit }\end{array}$ & Perhitungan & Skor & Klasifikasi \\
\hline Solopurwosari & $\frac{2,67}{9} \times 100 \%$ & $33 \%$ & "Mendekati \\
Solobalapan & $\frac{2,67}{9} \times 100 \%$ & $33 \%$ & $\begin{array}{c}\text { tidak } \\
\text { sesuai" }\end{array}$ \\
\cline { 1 - 2 } Soloebres & $\frac{1,33}{9} \times 100 \%$ & $17 \%$ & \\
\hline
\end{tabular}

Sumber: Analisis Peneliti, 2017

Berdasarkan tabel di atas dapat disimpulkan bahwa Kawasan Transit Solopurwosari, Kawasan Transit Solobalapan, dan Kawasan Transit Solojebres merupakan kawasan transit di Kota Surakarta yang termasuk ke dalam kategori mendekati tidak sesuai dengan konsep Transit-Oriented Development (TOD). Penilaian tersebut didasarkan pada skor ketiga kawasan yang berada dalam kelas 0\%-49\%. Dari hasil analisis yang telah dilakukan, kawasan transit Solopurwosari dan Solobalapan diketahui memenuhi dua prinsip konsep TOD, yaitu interkoneksi jalan serta ketersediaan ruang terbuka. Sementara kawasan transit Solojebres hanya memenuhi satu dari enam prinsip yang ada yaitu interkoneksi jalan.

\section{KESIMPULAN}

Hasil penelitian yang telah dilakukan menunjukkan bahwa kawasan transit Solopurwosari, kawasan transit Solobalapan, dan kawasan transit Solojebres termasuk ke dalam kategori mendekati tidak sesuai dengan konsep Transit Oriented Development. Dari 6 prinsip konsep TOD, hanya 1 - 2 kriteria yang terpenuhi pada masing-masing kawasan. Temuan ini menandakan bahwa penerapan konsep Transit Oriented Development di titik-titik transit di Kota Surakarta masih perlu dikembangkan, khususnya pada aspekaspek dasar yang menjadi karakteristik kawasan TOD yaitu kepadatan penggunaan lahan dan bangunan, pemanfaatan lahan campuran untuk mendekatkan berbagai aktivitas, infrastruktur yang aman bagi pejalan kaki dan pesepeda serta ketersediaan lahan parkir kolektif sebagai langkah efisensi penggunaan lahan. Pemenuhan prinsip-prinsip tersebut perlu dilaksanakan secara menyeluruh mengingat keenamnya saling terkait untuk mencapai konsep TOD yang berkelanjutan.

Berdasarkan hasil temuan diatas, rekomendasi yang dapat diusulkan untuk kawasan transit Solopurwosari, Solobalapan dan Solojebres adalah sebagai berikut:

- Bagi pemerintah Kota Surakarta

Pemerintah kota Surakarta dapat menjadikan bahan pertimbangan dalam menyusun rencana tata ruang dari beberapa aspek dasar yang belum terklasifikasikan sesuai dengan prinsip konsep TOD. Seperti dalam aspek tata guna lahan, rencana pola ruang kota Surakarta, terutama kawasan disekitar Stasiun Solopurwosari, Solobalapan dan Solojebres dapat diarahkan untuk dikembangkan memiliki penggunaan lahan dengan intensitas tinggi dan variatif (mixed-uses). Sementara dalam rencana struktur ruang, pengembangan jaringan pesepeda dan pedestrian menjadi alternatif strategi dalam usaha membentuk lingkungan yang ramah pejalan kaki dan pesepeda. Masukan lainnya yang dapat diambil adalah mengembangkan sistem parkir kendaraan bersama/kolektif. Hal tersebut selain bertujuan untuk meningkatkan efisensi penggunaan lahan juga membatasi visual yang bertentangan dengan prinsip ramah pejalan kaki dan bersepeda

- Penelitian selanjutnya

Penerapan konsep Transit-Oriented Development saling mengkaitkan aspek tata ruang dan transportasi. Oleh karena itu perlu juga 
melakukan kajian terhadap aspek transportasi konsep TOD terkait dengan pengembangan sistem transportasi masal. Dengan melakukan penelitian tersebut, maka diperoleh hasil/masukan kawasan ber konsep TOD dalam satu kesatuan. Penelitian terkait TOD lainnya yang dapat diambil adalah kajian konsep TOD untuk titik-titik transit Kota Surakarta lainnya yang berpotensi untuk dikembangkan dengan konsep TOD.

\section{REFERENSI}

Bishop, Zane. 2015. Transit-Oriented Development: Benefits and Studies. Virginia: Ball State University

Calthrope Associates. 1993. TransitOriented Development Design Concepts. San Jose: Transpotation Agency

Dokumen Tatanan Transportasi Lokal (Tatralok) Kota Surakarta Tahun 2009

Dittmar, Hank and Gloria. 2003. The New Transit Town: Best Practices In Transit-Oriented Development. Washington DC: Islan Press

ITDP (Institute for Transportation Development Policy). 2015. TOD Standard. Despachio: New York

Griffin, Kenneth W. 2004. Building Type Basics for Transit Facilities. Ann Arbor: John Wiley \& Sons

Rencana Tata Ruang Wilayah (RTRW) Kota Surakarta 20112031

Tamin, Ofyar Z. 2000. Perencanaan dan Permodelan Transportasi. Bandung: ITB Press

TCRP (Transit Cooperative Research Program). 2002. Transit-Oriented Development and Joint Development in the United States: A Literature Review. Washington DC: Transportation Research (http://online pubs.trb.org/onlinepubs/tcrp/tcr p_rrd_52.pdf)

TCRPC (Treasure Coast Regional Planning Council). 2012. Florida TOD Guidebook. Tallahassee: Florida Department of Transportation

Srihadi, Endang. 2010. "Problem Kemacetan Jakarta" 2010. Update Indonesia, Volume V No. 5: 2-3 